\title{
The Effect of Intravenous Autologous Activated Platelet-Rich Plasma Therapy on "Profibrotic Cytokine" IL-1 $\beta$ Levels in Severe and Critical COVID-19 Patients: A Preliminary Study
}

\author{
Karina Karina $\mathbb{D}^{1},{ }^{1,2,3,4}$ Louis Martin Christoffel, ${ }^{5}$ Rita Novariani, ${ }^{5}$ Imam Rosadi $\left(\mathbb{D},{ }^{2,6}\right.$ \\ Iis Rosliana, ${ }^{2}$ Siti Rosidah, ${ }^{5}$ Siti Sobariah, ${ }^{2}$ Novy Fatkhurohman, \\ Nurlaela Puspitaningrum, ${ }^{5}$ Yuli Hertati, ${ }^{5}$ Irsyah Afini, ${ }^{2}$ Difky Ernanda, ${ }^{2}$ Tias Widyastuti, ${ }^{2}$ \\ A. D. Sulaeha, ${ }^{1}$ Alfida Zakiyah, ${ }^{2}$ Noor Aini, ${ }^{2}$ Grady Krisandi, ${ }^{2,7}$ and Hubert Andrew ${ }^{2,7}$ \\ ${ }^{1}$ Klinik Hayandra, Yayasan Hayandra Peduli, Jl. Kramat VI No. 11, Jakarta, Indonesia \\ ${ }^{2}$ HayandraLab, Yayasan Hayandra Peduli, Jl. Kramat VI No. 11, Jakarta, Indonesia \\ ${ }^{3}$ Universitas Pembangunan Nasional Veteran Jakarta, Jakarta, Indonesia \\ ${ }^{4}$ Pusat Kajian Stem Cell, Universitas Pembangunan Nasional Veteran Jakarta, Jakarta, Indonesia \\ ${ }^{5}$ Koja Regional Public Hospital, Jl. Deli No. 4, Jakarta, Indonesia \\ ${ }^{6}$ Department of Biology, Faculty of Mathematics and Natural Sciences, Mulawarman University, Samarinda, Indonesia \\ ${ }^{7}$ Universitas Indonesia, Jl. Salemba Raya No. 6, Jakarta, Indonesia
}

Correspondence should be addressed to Karina Karina; karina@hayandra.com

Received 16 April 2021; Revised 25 May 2021; Accepted 26 June 2021; Published 8 July 2021

Academic Editor: Vassilios I. Sikavitsas

Copyright (C) 2021 Karina Karina et al. This is an open access article distributed under the Creative Commons Attribution License, which permits unrestricted use, distribution, and reproduction in any medium, provided the original work is properly cited.

Introduction. Elevated concentration of proinflammatory cytokines followed by hyperinflammation is one of the hallmarks of severe and critical COVID-19. In the short term, this may result in ARDS and lung injury; subsequently, this may cause pulmonary fibrosis - a disease with poor prognosis-in the long run. Among the cytokines, interleukin-1 $\beta$ (IL- $1 \beta$ ) is one of the most overexpressed in COVID-19. We speculate that administration of intravenous activated autologous platelet-rich plasma (aaPRP), which contains interleukin-1 receptor antagonist (IL-1RA), would lower IL-1 $\beta$ levels and benefit the severe and critical COVID-19 patients. Methods. After acquiring ethical clearance, we recruited 12 adult COVID-19 patients of both sexes from the Koja Regional Hospital (Jakarta, Indonesia) ICU. After selection, seven patients were included and divided into two groups, severe and critical. In addition to three doses of aaPRP, both groups received the same treatment of antiviral, steroid, and antibiotics. Quantification of plasma IL- $1 \beta$ levels was performed by beads multiplex assay a day before the first aaPRP administration and a day after the second and third aaPRP administration. $\mathrm{PaO}_{2} / \mathrm{FiO}_{2}$ ratio and lung injury scores were evaluated a day before and a day after each aaPRP administration. Results. Severe and critical patients' initial plasma IL- $1 \beta$ concentration was $4.71 \mathrm{pg} / \mathrm{mL}$ and $3.095 \mathrm{pg} / \mathrm{mL}$, respectively. After 2 treatments with aaPRP, severe patients' plasma IL- $1 \beta$ concentration decreased $12.48 \mathrm{pg} / \mathrm{mL}$, while critical patients' plasma IL- $1 \beta$ concentration increased to $18.77 \mathrm{pg} / \mathrm{mL}$. Furthermore, after 3 aaPRP treatments, significant amelioration of patients' $\mathrm{PaO}_{2} / \mathrm{FiO}_{2}$ ratio from $71.33 \mathrm{mmHg}$ at baseline to $144.97 \mathrm{mmHg}$ was observed $(p<0.05)$. However, no significant improvement in lung injury score was observed in severe and critical groups. All severe patients and one critical patient recovered. Conclusion. The use of aaPRP may prevent pulmonary fibrosis in severe COVID-19 patients through the reduction of patients' plasma IL- $1 \beta$ concentration and the amelioration of $\mathrm{PaO}_{2} / \mathrm{FiO}_{2}$ ratio. 


\section{Introduction}

COVID-19 causes mortality through the process of cytokine storm, which is hyperinflammation and multiorgan damage triggered by uncontrolled release of cytokines. [1] The elevated concentration of proinflammatory cytokines is associated with severe COVID-19 and may result in complications such as acute respiratory distress (ARDS), sepsis, and respiratory failure [1-3]. Such cytokine storms can cause acute lung injury, which, in turn, may induce pulmonary fibrosis $[4,5]$. It is estimated that over a third of recovered patients develop fibrotic abnormalities upon radiological examination. As more and more patients recover, post-COVID-19 pulmonary fibrosis is already starting to be reported [6].

Pulmonary fibrosis is a form of chronic, progressive, fibrosing interstitial pneumonia. It is irreversible, has an unpredictable clinical course, and is associated with extremely poor prognosis [7]. As its prevalence is already increasing from other causes [8], additional cases from COVID-19 would give rise to a remarkable morbidity and mortality rate as repercussion. Currently, no definitive cure exists for the condition except for lung transplantation. [9].

Among the overexpressed cytokine present in cytokine storms is interleukin-1 beta (IL-1 $\beta$ ), which is also implied in the pathogenesis of pulmonary fibrosis [10]. Activated autologous platelet-rich plasma (aaPRP) is a prospective therapy to be performed in COVID-19 patients to combat such systemic inflammation. Apart from its accessibility, it also possesses anti-inflammatory properties through cytokines such as interleukin-1 receptor antagonist (IL-1RA) and a known safety profile [11-14]. Similarly, anakinra, a recombinant IL1-RA, showed promising results in a cohort consisting of patients with severe forms COVID-19 [15].

To our knowledge, no research on the influence of aaPRP administration on cytokine profile in COVID-19 patients has been published previously. Hence, in this study, we explored the effect of intravenous (IV) aaPRP administration on the plasma levels of IL- $1 \beta$-a profibrotic and proinflammatory cytokine in severe and critical COVID-19 patients.

\section{Methods}

This interventional preliminary study recruited 12 patients of both sexes between the age of 18-65. The study protocol was ethically approved by the Health Research Ethics Committee, University of Indonesia and Cipto Mangunkusumo Hospital (HREC-FMUI/CMH), and is registered on ClinicalTrials.gov (NCT04715360).

The inclusion criterion for the study was severe or critical COVID-19 patient being treated in the Koja Regional Public Hospital (Jakarta, Indonesia) ICU. Meanwhile, we excluded patients who were diagnosed with HIV, hepatitis, cancer, chronic kidney disease with ongoing dialysis, and pregnancy. Ultimately, we included seven patients, with three severe and four critical patients enrolled in the study. Critical patients differ from severe patients by the additional employment of mechanical ventilation and administration of vasopressors due to sepsis.

Both groups received Avigan (favipiravir) $1.600 \mathrm{mg}$ twice daily (b.i.d) for a day followed by $600 \mathrm{mg}$ b.i.d. for five consecutive days and oral or parenteral administration of dexamethasone $6 \mathrm{mg} / 24$ hours for 10 days. Oxygen therapy and antibiotics were given accordingly. The patients also received intravenous (IV) aaPRP on day 1,3 , and 5 , while quantification of plasma IL- $1 \beta$ levels was conducted by the FMUI Integrated Laboratory on day 0 , 4, and 6 with $\mathrm{PaO}_{2} /$ $\mathrm{FiO}_{2}$ ratio and lung injury scores recorded with the same intervals. The quantification method was MILLIPLEX ${ }^{\circledR}$ (HCTYTA-60K) beads multiplex assay (Merck, Burlington, Massachusetts), and results were read with the Luminex 200 and Luminex xPONENT (Luminex, Austin, Texas).

aaPRP was prepared using the method invented and developed by HayandraLab. Venous whole blood was collected from each patient into eight sodium citrate tubes and centrifuged at $1.000 \mathrm{rpm}$ for 10 minutes. Blood plasma was then separated and centrifuged at $3.000 \mathrm{rpm}$ for another 10 minutes until platelet sediment formed. The platelet-poor part of the plasma was discarded, and the subsequent plasma was reckoned as inactivated PRP. Activation was achieved by the addition of a calcium activator (H-Remedy, HayandraLab, Indonesia), and the consequent clots were then removed. Finally, the aaPRP was suspended in normal saline and administered intravenously to the patients.

\section{Statistical Analysis}

The paired $T$-test was used to analyze severe, recovered, and dead patients' plasma IL- $1 \beta$ profile, and the Friedman test was used to analyze critical patients' plasma IL- $1 \beta$ profile. Plasma IL-1 $\beta$ profile was further analyzed to compare the profile between the severe-critical group and recovered-dead patients using the Mann-Whitney $U$ test. The patients' $\mathrm{PaO}_{2} / \mathrm{FiO}_{2}$ ratio was analyzed using the Friedman test. To compare the $\mathrm{PaO}_{2} / \mathrm{FiO}_{2}$ ratio in the severe and critical group, the Mann-Whitney test and independent sample $T$ test were used. The patients' lung injury score was analyzed using the Friedman test. For comparison of lung injury score in the severe and critical group, the Mann-Whitney $U$ test and independent sample $T$-test were used.

\section{Results}

4.1. Demography of Patients and Chest X-Ray Finding. A total of 7 patients participated in this study with 3 severe patients (median age: 41 years, $34-55$ years) and 4 critical patients (median age: 58 years, 48-61 years). The median age of all patients was 55 years. The youngest patient was 34 years old, and the oldest was 61 years old. All the patients had ARDS and underwent chest $\mathrm{x}$-ray examination with 3 severe patients and 1 critical patient having bilateral pneumonia and 3 critical patients having bilateral opacity. Among the 4 patients who had bilateral pneumonia, 1 critical patient had extensive bilateral pneumonia. All the patients also had underlying comorbidities with some patients having more than 1 underlying comorbidity. The most common 
underlying comorbidity was type II diabetes mellitus, followed by hypertension, congestive heart failure, obesity, and acute kidney injury. The summary of patients' demography is shown in Table 1.

4.2. Patients' Plasma Interleukin-1 $\beta$ Concentration and Outcome after Activated Autologous Platelet-Rich Plasma Administration. Patients' plasma IL- $1 \beta$ profile after aaPRP administration differed between severe and critical patients. Severe patients who underwent aaPRP treatment had a trend of decrease in plasma IL- $1 \beta$ concentration from $4.71 \mathrm{pg} / \mathrm{mL}$ to $2.48 \mathrm{pg} / \mathrm{mL}$, while critical patients who underwent aaPRP treatment had their plasma IL- $1 \beta$ increased from $3.095 \mathrm{pg} /$ $\mathrm{mL}$ to $18.77 \mathrm{pg} / \mathrm{mL}$ Figure 1 . However, both trends were not statistically significant $(p>0.05)$. Furthermore, no statistical significance was observed between the 2 groups $(p>0.05)$. Among the 7 patients who were included in this study, all severe patients and 1 critical patient recovered, while 3 other critical patients died in this study. Patients who recovered had a decreasing trend in plasma IL- $1 \beta$ concentration by day 6 of the study, while patients who died had their plasma IL$1 \beta$ concentration increased by day 4 and 6 Figure 2 . However, these findings were not statistically significant $(p>0.05)$. Moreover, no statistical significance was observed between the 2 groups $(p>0.05)$.

\subsection{Patients' $\mathrm{PaO}_{2} / \mathrm{FiO}_{2}(\mathrm{PF})$ Ratio after Activated Autologous} Platelet-Rich Plasma Administration. Patients' $\mathrm{P} / \mathrm{F}$ ratio was ameliorated after 3 aaPRP administration. A statistically significant increase was observed between before aaPRP administration and after 3 aaPRP administration from $71.33 \mathrm{mmHg}$ to $144.97 \mathrm{mmHg}(p<0.05)$. Furthermore, a statistically significant increase was also observed between the $2^{\text {nd }}$ and $3^{\text {rd }}$ aaPRP administration from $103.7 \mathrm{mmHg}$ to $144.97 \mathrm{mmHg}(p<0.05)$. However, no statistical significance was observed between the severe and critical group $(p>0.05)$, Figure 3 .

4.4. Patients' Lung Injury Score after Activated Autologous Platelet-Rich Plasma Administration. Patients' average lung injury score increased after 2 aaPRP administration from 5.33 to 6.50 and decreased to 6.00 after the $3^{\text {rd }}$ aaPRP administration. However, the changes of lung injury score after aaPRP administrations were not statistically significant. Moreover, no statistical significance was observed between the severe and critical group $(p>0.05)$ (Figure 4$)$.

\section{Discussion}

Currently, favipiravir is the choice antiviral medication for the treatment of severe and critical COVID-19 patients in Indonesia. Along with favipiravir, dexamethasone is also recommended in for severe and critical patients requiring breathing aid such as oxygen therapy and ventilator [16]. Immunosuppressive therapy along with invasive device usage (such as endotracheal tube for mechanical ventilation) contributes to nosocomial bacterial and fungal infection risk in COVID-19 patients treated in the intensive-care unit (ICU) [17]. Infections may appear as early as one week of ICU stay and significantly extend ICU hospitalization duration [18]; meropenem is given to treat such infection.

Oxygen therapy is initiated if patient peripheral oxygen saturation $\left(\mathrm{SpO}_{2}\right)$ falls below 93\% with a nasal cannula (NC) escalating to a nonrebreather mask (NRM); the target $\mathrm{SpO}_{2}$ for such therapy is $92-96 \%$. In the event that patient $\mathrm{SpO}_{2}$ does not improve after 1 hour of initial oxygen therapy, it is indicated to switch to a high-flow nasal cannula (HFNC). Reevaluation is then performed after two hours to decide whether the patient needs invasive ventilation or not [16]. The maximum achievable fraction of inspired oxygen $\left(\mathrm{FiO}_{2}\right)$ depends on the device used to deliver the oxygen, Table 2. In our ICU, the preferred oxygen therapy is NRM, followed by HFNC and intubation as the last resort. The weaning process was performed by deescalating from a ventilator to an NRM, simple mask, and then, NC.

Huang et al. noted that IL- $1 \beta$, which during cytokine storms is among the most important cytokines in the IL-1 family, is markedly increased in COVID-19 patients $[2,19]$. Infection by SARS-CoV-2 induces the release of a proinflammatory cytokine such as IL-1 $\beta$ through activation of TLR2 (toll-like receptor 2), TLR3, or TLR4 [20]. IL-1 $\beta$ plays an important role in the pathogenesis of pulmonary fibrosis by inducing overexpression of TGF- $\beta 1$, which, in turn, causes a progression to fibrosis via fibroblast differentiation and activation into myofibroblasts $[10,21]$. The myofibroblasts cause excessive ECM accumulation which ultimately leads to loss of alveolar function [10].

Blockage of IL- $1 \beta$ for COVID-19 is studied in numerous studies. Canakinumab is a fully human IgG monoclonal antibody which targets IL- $1 \beta$. Previously, the efficacy of canakinumab for treatment of COVID-19 was evaluated in CANASCOV, an observational cohort-prospective study; the study progressed to a phase III clinical trial (CANCOVID) but was suspended due to unsatisfactory interim analysis results $[22,23]$. Another IL-1 receptor antagonist, anakinra, was also explored as treatment for COVID-19 in several studies. However, evidence to support anakinra use is still deemed insufficient [24].

Our study aimed at reducing IL- $1 \beta$ levels as well as its effects in the body. As mentioned before, aaPRP contains IL$1 \mathrm{RA}$, the endogenous antagonist to IL-1 receptors $[11,12]$. It is thought that blockage of IL-1 receptors would reduce inflammation and also fibrosis progression in the long run. While both groups received aaPRP treatment in this study, all the severe patients recovered while only one out of four critical patients survived. It is also observed that IL- $1 \beta$ levels are inversely correlated with favorability of patient outcome. Utilization of this relationship may be a valuable predictive biomarker for mortality in COVID-19. However, as all these findings are not statistically significant, it should be interpreted wisely.

We noted the initial increase and subsequent decrease in IL- $1 \beta$ levels in patients who recover, while those who died had IL- $1 \beta$ levels that continued to increase throughout the study. We speculated that the immunomodulatory effects of aaPRP can prevent sepsis in severe patients [25]. However, in 
TABLE 1: Demography of patients and chest x-ray findings.

\begin{tabular}{|c|c|c|c|c|c|c|c|}
\hline $\begin{array}{l}\text { Patient } \\
\text { code }\end{array}$ & Group & Sex & Age & Comorbidities & Chest x-ray & ARDS & Outcome \\
\hline PRP 1 & & $\mathrm{~F}$ & 55 & Type II diabetes mellitus and obesity & Bilateral pneumonia & & Recovered \\
\hline PRP 8 & Severe & $\mathrm{F}$ & 34 & Hypertension & Bilateral pneumonia & Yes & Recovered \\
\hline PRP 10 & & $\mathrm{M}$ & 41 & Obesity & Bilateral pneumonia & & Recovered \\
\hline PRP 2 & & $\mathrm{~F}$ & 48 & Hypertension & $\begin{array}{l}\text { Extensive bilateral } \\
\text { pneumonia }\end{array}$ & & Dead \\
\hline PRP 7 & & $\mathrm{~F}$ & 56 & Type II diabetes mellitus and obesity & Total bilateral opacity & & Recovered \\
\hline PRP 11 & Critical & $\mathrm{F}$ & 61 & $\begin{array}{l}\text { Type II diabetes mellitus, congestive heart failure, and } \\
\text { acute kidney injury }\end{array}$ & $6 / 3$ bilateral opacity & Yes & Dead \\
\hline PRP 12 & & $\mathrm{M}$ & 60 & $\begin{array}{l}\text { Type II diabetes mellitus, hypertension, and congestive } \\
\text { heart failure }\end{array}$ & $2 / 3$ bilateral opacity & & Dead \\
\hline
\end{tabular}

Severe and critical patient's plasma IL- $1 \beta$ profile



Severe patient's plasma IL- $1 \beta$ profile $(\mathrm{pg} / \mathrm{mL})$

Critical patient's plasma IL- $1 \beta$ profile $(\mathrm{pg} / \mathrm{mL})$

FIgURE 1: Severe and critical patients' plasma IL-1 $\beta$ profile.



FIgURE 2: Recovered and dead patients' plasma IL-1 $\beta$ profile.

those who are classified as critical and already suffering from sepsis, aaPRP was not able to lower IL-1 $\beta$ concentration. Viral septic shock is cited as one of the most notorious cause for death in COVID-19 patients [26]. The initial increase may be a sign of a septic shock that was averted by administration of aaPRP, with the delay in IL- $1 \beta$ decrease 
$\mathrm{PaO}_{2} / \mathrm{FiO}_{2}$ ratio



FIgure 3: Patients' $\mathrm{PaO}_{2} / \mathrm{FiO}_{2}$ ratio after aaPRP administration.

Lung injury score

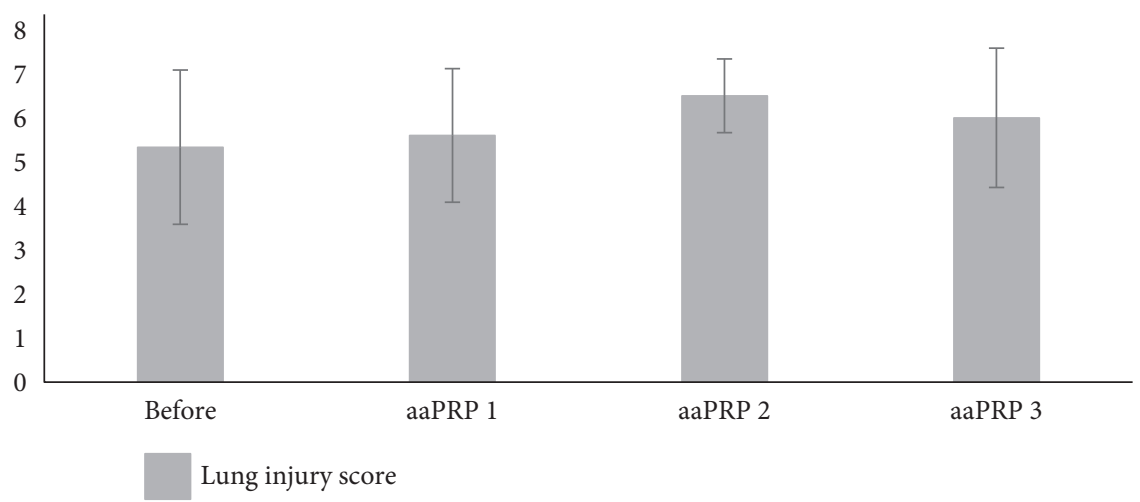

FIgURE 4: Patients' lung injury score after aaPRP administration.

TABLE 2: Various oxygen delivery devices.

\begin{tabular}{lcc}
\hline Device & Flow $(\mathrm{L} /$ minute $)$ & Achievable $\mathrm{FiO}_{2}$ \\
\hline Nasal cannula & $3-6$ & Maximum $\sim 30 \%$ \\
Simple mask & $6-8$ & Maximum $\sim 60 \%$ \\
Rebreathing mask & $10-12$ & Maximum $\sim 80 \%$ \\
Nonrebreather mask & $12-15$ & Maximum $\sim 95 \%$ \\
High-flow nasal cannula & $25-60$ & $40-100 \%$ \\
Intubation & $30-40$ & Any $\mathrm{FiO}_{2}$ \\
\hline
\end{tabular}

showing that aaPRP needs time before exerting therapeutic effects. As these findings are unconfirmed, future studies should verify these results.

The therapeutic effect of PRP on lung injury has been studied before in vivo by Mammoto et al. [27]. They found PRP to contain various types of angiogenic factors such as angiopoietin-1 and VEGF, which is required for physiological angiogenesis-as opposed to a single angiogenic factor. These angiogenic factors are thought to be the rationale of the vascular and alveolar regeneration observed in the study. Nebulized PRP is also studied for its effects in COVID-19 in vitro. Beitia et al. [28] hypothesized that the administration of PRP results in the reduction of fibrosis and the regeneration of damaged pulmonary tissue.

We noted statistically significant improvements in $\mathrm{PaO}_{2} /$ $\mathrm{FiO}_{2}(\mathrm{P} / \mathrm{F})$ ratio in our patients over the course of the treatment. Although, it should be noted that, during the duration of the study, none of the patients' $\mathrm{PaO}_{2} / \mathrm{FiO}_{2}$ increased above $300 \mathrm{mmHg}$. This means all seven patients were still experiencing acute respiratory distress syndrome (ARDS) after the third dose of aaPRP. This result is consistent with the patients' lung injury score which was still above 2.5 after the final dose of aaPRP, indicating the presence of ARDS.

Several modalities have been used to treat severe and critical COVID-19 patients. Among the available modalities, the use of mesenchymal stem cells (MSCs) has been popular ever since due to its immunomodulatory properties [29]. The immunomodulatory properties of MSCs are also known to reduce concentration of fibrotic factors and prevent pulmonary fibrosis in COVID-19 patients. However, the use of MSCs for COVID-19 patients is usually not feasible. The first reason is because collection of autologous MSCs from the patient's own body is not likely to be performed. 
Furthermore, severe and critical COVID-19 patients are usually present with inflammatory-related comorbidities, such as diabetes mellitus, which reduces the ability of MSCs to expand [30]. Thus, the reduced ability of MSCs to expand will delay the time for more than 2 weeks until it reaches the required dose which will also delay the treatment for severe and critical COVID-19 patients. [31].

As for allogenic MSCs, it has limited potency and safety for use in severe and critical COVID-19 patients. First, it requires healthy donors for the source of MSCs. Second, donor screening and cell characterization are required before the use of allogenic MSCs to prevent immunological rejections and infections. Third, it still requires expansion of MSCs which takes around 2 weeks. Lastly, MSCs are no longer found to be immuneprivileged by diminishing HLA-DR because the reexpression of HLA-DR in certain conditions, such as inflammation, may induce immune responses, especially in severe and critical COVID-19 patients where inflammation is prominent [32-34].

As the use of autologous and allogenic MSCs to prevent pulmonary fibrosis is not feasible in COVID-19 patients, aaPRP is a more feasible potential alternative to prevent pulmonary fibrosis in severe and COVID-19 patients. This is because aaPRP can easily be isolated and processed from the patient's venous blood which only requires around 2 hours until it is administered intravenously to the patient. Furthermore, aaPRP has been proven to be safe because it is free of platelets, as proven in our previous studies, which does not cause thrombosis [14].

Nevertheless, there are still several limitations in our study. First, our study is a preliminary study that uses aaPRP to prevent pulmonary fibrosis in only 7 COVID-19 patients. Second, we only present the effect of aaPRP on the concentration of IL- $1 \beta$ as a profibrotic parameter. Third, no control patients were included in this study to confirm the reduction of IL- $1 \beta$ by aaPRP. Therefore, a bigger sample study on the use of aaPRP to prevent pulmonary fibrosis in severe and critical COVID-19 patients with control and long-term follow-up is required.

\section{Conclusions}

The use of aaPRP in severe COVID-19 patients is found to reduce their plasma IL-1 $\beta$ concentration which is beneficial to prevent pulmonary fibrosis after they have recovered. As for critical COVID-19 patients, their plasma IL- $1 \beta$ concentration increased but one of the patients recovered from COVID-19. Furthermore, patients' $\mathrm{PaO}_{2} / \mathrm{FiO}_{2}$ ratio improved significantly indicating improvement of lung function.

\section{Data Availability}

The data used to support the findings in this study are included within the article.

\section{Conflicts of Interest}

The authors declare that they have no conflicts of interest.

\section{References}

[1] L. A. Henderson, S. W. Canna, G. S. Schulert et al., "On the alert for cytokine storm: immunopathology in COVID -19," Arthritis and Rheumatology, vol. 72, no. 7, pp. 1059-1063, 2020.

[2] C. Huang, Y. Wang, X. Li et al., "Clinical features of patients infected with 2019 novel coronavirus in Wuhan, China," The Lancet, vol. 395, no. 10223, pp. 497-506, 2020.

[3] D. K. Rai, P. Sharma, and R. Kumar, "Post covid 19 pulmonary fibrosis- Is it real threat?" Indian Journal of Tuberculosis, vol. 68, no. 3, pp. 330-333, 2020.

[4] A. S. Ojo, S. A. Balogun, O. T. Williams, and O. S. Ojo, "Pulmonary fibrosis in COVID-19 survivors: predictive factors and risk reduction strategies," Pulmonary Medicine, vol. 2020, Article ID 6175964, 10 pages, 2020.

[5] P. Spagnolo, E. Balestro, S. Aliberti et al., "Pulmonary fibrosis secondary to COVID-19: a call to arms?" The Lancet Respiratory Medicine, vol. 8, no. 8, pp. 750-752, 2020.

[6] M. Ahmad Alhiyari, F. Ata, M. Islam Alghizzawi, A. Bint I Bilal, A. Salih Abdulhadi, and Z. Yousaf, "Post COVID-19 fibrosis, an emerging complicationof SARS-CoV-2 infection," IDCases, vol. 23, Article ID e01041, 2021.

[7] G. Raghu, H. R. Collard, J. J. Egan et al., "An Official ATS/ ERS/JRS/ALAT Statement: idiopathic pulmonary fibrosis: evidence-based guidelines for diagnosis and management," American Journal of Respiratory and Critical Care Medicine, vol. 183, no. 6, pp. 788-824, 2011.

[8] L. Nalysnyk, J. Cid-Ruzafa, P. Rotella, and D. Esser, "Incidence and prevalence of idiopathic pulmonary fibrosis: review of the literature," European Respiratory Review, vol. 21, pp. 355-361, 2012.

[9] P. M. George, C. M. Patterson, A. K. Reed, and M. Thillai, "Lung transplantation for idiopathic pulmonary fibrosis," The Lancet Respiratory Medicine, vol. 7, no. 3, pp. 271-282, 2019.

[10] K. Lechowicz, S. Drożdżal, F. Machaj et al., "COVID-19: the potential treatment of pulmonary fibrosis associated with SARS-CoV-2 infection," Journal of Clinical Medicine, vol. 9, no. 6, 1917 pages, 2020.

[11] J. M. Cassano, J. G. Kennedy, K. A. Ross, E. J. Fraser, M. B. Goodale, and L. A. Fortier, "Bone marrow concentrate and platelet-rich plasma differ in cell distribution and interleukin 1 receptor antagonist protein concentration," Knee Surgery, Sport Traumatology Arthroscopy, vol. 26, pp. 333342, 2018.

[12] S. Wasai, M. Sato, M. Maehara et al., "Characteristics of autologous protein solution and leucocyte-poor platelet-rich plasma for the treatment of osteoarthritis of the knee," Scientific Reports, vol. 10, Article ID 10572, 2020.

[13] K. Karina, I. Rosliana, I. Rosadi et al., "Safety of technique and procedure of stromal vascular fraction therapy: from liposuction to cell administration," Scientifica (Cairo), vol. 2020, Article ID 2863624, 11 pages, 2020.

[14] K. Karina, K. Ekaputri, J. A. Biben et al., "Evaluating the safety of intravenous Delivery of autologous activated platelet-rich plasma," Journal of Health Science, 2021, Internet.

[15] T. Huet, H. Beaussier, O. Voisin et al., "Anakinra for severe forms of COVID-19: a cohort study," Lancet Rheumatology, vol. 2, no. 7, pp. e393-e400, 2020.

[16] E. Burhan, A. D. Susanto, S. A. Nasution et al., "Pedoman tatalaksana COVID-19," in Jakarta: Perhimpunan Dokter Paru Indonesia (PDPI), E. Burhan, A. D. Susanto, F. Isbaniah et al., Eds., vol. 21p. 55, 3rd edition, 2020. 
[17] Y. He, W. Li, Z. Wang, H. Chen, L. Tian, and D. Liu, "Nosocomial infection among patients with COVID-19: a retrospective data analysis of 918 cases from a single center in Wuhan, China," Infection Control and Hospital Epidemiology, vol. 41, no. 8, pp. 982-983, 2020.

[18] T. Bardi, V. Pintado, M. Gomez-Rojo et al., "Nosocomial infections associated to COVID-19 in the intensive care unit: clinical characteristics and outcome," European Journal of Clinical Microbiology and Infectious Diseases, vol. 40, no. 3, pp. 495-502, 2021.

[19] Q. Ye, B. Wang, and J. Mao, "The pathogenesis and treatment of the "cytokine storm" in COVID-19," Journal of Infection, vol. 80, pp. 607-613, 2020.

[20] P. Conti, G. Ronconi, A. Caraffa et al., "Induction of proinflammatory cytokines (IL-1 and IL-6) and lung inflammation by Coronavirus-19 (COVI-19 or SARS-CoV-2): antiinflammatory strategies," Journal of Biological Regulators \& Homeostatic Agents, vol. 34, no. 2, pp. 327-331, 2020.

[21] V. Masola, A. Carraro, S. Granata et al., "In vitro effects of interleukin (IL)-1 beta inhibition on the epithelial-to-mesenchymal transition (EMT) of renal tubular and hepatic stellate cells," Journal of Translational Medicine, vol. 17, no. 1, 12 pages, 2019.

[22] O. H. Alser and I. Goutos, "The evidence behind the use of platelet-rich plasma (PRP) in scar management: a literature review," Scars, Burns \& Healing, vol. 4, Article ID 2059513118808773, 2018.

[23] A. G. Novartis International, Novartis Provides Update on CAN-COVID Trial in Hospitalized Patients with COVID-19 Pneumonia and Cytokine Release Syndrome (CRS) | Novartis [Internet], https://www.novartis.com/news/media-releases/ novartis-provides-update-can-covid-trial-hospitalizedpatients-covid-19-pneumonia-and-cytokine-releasesyndrome-crs, 2020.

[24] F. A. Khan, I. Stewart, L. Fabbri et al., "Systematic review and meta-analysis of anakinra, sarilumab, siltuximab and tocilizumab for COVID-19," Thorax, 2021, Internet.

[25] C. N. Jenne, R. Urrutia, and P. Kubes, "Platelets: bridging hemostasis, inflammation, and immunity," International Journal of Laboratory Hematology, vol. 35, no. 3, pp. 254-261, 2013.

[26] J. Beltrán-García, R. Osca-Verdegal, F. V. Pallardó et al., "Sepsis and coronavirus disease 2019: common features and anti-inflammatory therapeutic approaches," Critical Care Medicine, vol. 48, no. 12, pp. 1841-1844, 2020.

[27] T. Mammoto, Z. Chen, A. Jiang, E. Jiang, D. E. Ingber, and A. Mammoto, "Acceleration of lung regeneration by plateletrich plasma extract through the low-density lipoprotein receptor-related protein 5-tie2 pathway," American Journal of Respiratory Cell and Molecular Biology, vol. 54, no. 1, pp. 103-113, 2016.

[28] M. Beitia, D. Delgado, P. Sánchez, A. V. de la Cueva, J. R. Cugat, and M. Sánchez, "Platelet lysate nebulization protocol for the treatment of covid-19 and its sequels: proof of concept and scientific rationale," International Journal of Molecular Sciences, vol. 22, no. 4, 1856 pages, 2021.

[29] K. Rajarshi, A. Chatterjee, and S. Ray, "Combating COVID-19 with mesenchymal stem cell therapy," Biotechnology Reports, vol. 26, Article ID e00467, 2020.

[30] Karina, K. A. Wahyuningsih, S. Sobariah et al., "Evaluation of platelet-rich plasma from diabetic donors shows increased platelet vascular endothelial growth factor release," Stem Cell Investigation, vol. 6, no. 6, p. 43, 2019.
[31] A. Tzouvelekis, R. Toonkel, T. Karampitsakos et al., "Mesenchymal stem cells for the treatment of idiopathic pulmonary fibrosis," Frontiers in Medicine, vol. 5, no. MAY, pp. 142-148, 2018.

[32] M. Kot, M. Baj-Krzyworzeka, R. Szatanek, A. MusiałWysocka, M. Suda-Szczurek, and M. Majka, "The importance of hla assessment in "off-the-shelf" allogeneic mesenchymal stem cells based-therapies," International Journal of Molecular Sciences, vol. 20, no. 22, Article ID 20225680, 2019.

[33] W. T. Tse, J. D. Pendleton, W. M. Beyer, M. C. Egalka, and E. C. Guinan, "Suppression of allogeneic T-cell proliferation by human marrow stromal cells: implications in transplantation," Transplantation, vol. 75, no. 3, pp. 389-397, 2003.

[34] D. E. Leisman, L. Ronner, R. Pinotti et al., "Cytokine elevation in severe and critical COVID-19: a rapid systematic review, meta-analysis, and comparison with other inflammatory syndromes," The Lancet Respiratory Medicine, vol. 8, no. 12, pp. 1233-1244, 2020. 